\title{
Phyto-molecules for Kidney Stones Treatment and Management
}

\section{Gupta S and Kanwar SS*}

Department of Biotechnology, Himachal Pradesh University, Summer Hill, Shimla-171 005, India

\begin{abstract}
It has been centuries since humans are being affected by kidney stones or urolithiasis. In the past decade, in rural and the urban sectors, kidney stone cases are rising at an alarming rate having a high relapse rate. The rate and prevalence of urolithiasis has been attributed to a number of factors such as age, fluid intake, infections of the urinary tract, climatic conditions sex, genetic predisposition, ethnicity as well as diet. Kidney stones may cause extreme pain and blockage of urine flow, urinary tract infection, hydronephrosis and severe bleeding which necessitates the use of surgery in some cases to remove or break the stones. Although a number of treatments for kidney stones are available which include extracorporeal shock wave lithotripsy (ESWL) and drug therapy but the expensive nature of these therapies and the severe side effects caused by exposure to these shock waves such as acute renal injury, decreased renal function and increased stone recurrence limit their use. As proposed by several in vivo and in vitro studies and clinical trials, using phyto-molecules in the treatment and management of kidney stones has emerged as a novel option. The following study discuses about the various plants, their chemical constituents involved along with their mechanism of action that can be used for the treatment of kidney stones.
\end{abstract}

Keywords: Kidney stones; Urolithiasis; Nephrolithiasis; Phytomolecues; Calcium oxalate crystals; Prevention

\section{Introduction}

Affecting a good percentage of population around the globe including India, urolithiasis has become a common clinical disorder [1]. With the age of its onset is drastically decreasing, the events of kidney stones have been tremendously increasing since a decade or two [2]. Multiple factors such as those including diet, genetic, and low activity have been suggested to be responsible for this disorder $[3,4]$. Calcium oxalate and calcium phosphate are the most usual components of kidney stones, while magnesium ammonium phosphate (struvite), uric acid or cystine also form some proportion of them [5]. Nucleation, crystal growth, its aggregation and retention within the kidneys are the various events in the pathophisiology of calcium oxalate stone formation [1]. Several drugs and therapies have been employed in the cure of urolithiasis including thiazide diuretics, allopurinol, alkaline therapy [6], or other treatments like open or laproscopic stone removal, extracorporeal shock wave lithotripsy (ESWL), percutaneous nephrostolithotomy and ureteroscopy but none of them have proved to be fruitful for proper cure and prevention of recurrence of kidney stone, also exposure to shock waves may lead to severe side effects such as acute renal injury, increased stone recurrence and decreased renal function, also these treatments are expensive [2,7]. Therefore, several alternative therapies for the treatment of kidney stones are being explored. Numerous medicinal plants have been chosen as an effective treatment of urolithiasis as they inhibit kidney stone formation at various steps because of their antispasmodic, antioxidant and diuretic activities [8]. A number of plant extracts have been found to exhibit antilithogenic properties as they decrease the calcium ion concentration or increase citrate and magnesium excretion by changing the ion composition of urine [1].The motive of the following work is to critically review available literature on herbal medicines and their possible role in the management of urolithiasis.

\section{Types of Kidney Stones}

Several types of kidney stones have been reported owing to their composition and pathogenesis, which have been named after their mineral composition. Several techniques such as X-ray diffraction, optical crystallography and infrared spectroscopy have been utilized to identify the mineral components of kidney stones which have demonstrated that, in livestock and companion animals, oxalate, urate, struvite and cystine are the most important crystals [9-11]. Calcium oxalate is the most predominant component of kidney stones [12]. Stones are mainly composed of calcium. Principally calcium phosphate (apatite), calcium oxalate monohydrate (COM) also known as whewellite, calcium oxalate dehydrate (COD) also known as weddellite are the most commonly occurring stones in humans followed by cystiene, magnesium ammonium phosphate stones (struvite) and uric acid stones [13]. Stones such as those composed of silicate or the ones induced by drugs are produced by build-up chemicals in the urine by certain medications or herbal products [14].

\section{Mechanism of Kidney Stone Formation}

As already mentioned, the essence of formation of the stones (made up of calcium oxalate), lies in the supersaturation of the urine with calcium salts. Because of some metabolic abnormalities such as hypercalciuria, reduced urine volume, hyperoxaluria, an alteration in urine $\mathrm{pH}$, hypocitraturia, gouty diathesis and hyperuricosuria enhances stone formation by changing the composition and saturation of these stones $[15,16]$. Supersaturation is therefore the leading cause for crystallization in urine [17]. Stone formation involves a number of events such as (i) nucleation of stone constituent crystals, (ii) growth and aggregation of the stones so that they can interact with some intrarenal structure(s), (iii) holding the stones within the kidney or renal collecting system and (iv) aggregation and/ or secondary nucleation thereby forming clinical renal stone [18]. As compared to normal

*Corresponding author: Kanwar SS, Department of Biotechnology, Himacha Pradesh University, Summer Hill, Shimla-171 005, India, Tel: +91-177-2831948; E-mail: kanwarss2000@yahoo.com

Received: November 01, 2018; Accepted: November 12, 2018; Published November 19, 2018

Citation: Gupta S, Kanwar SS (2018) Phyto-molecules for Kidney Stones Treatment and Management. Biochem Anal Biochem 7: 362. doi: 10.4172/2161 1009.1000362

Copyright: $\odot 2018$ Gupta S, et al. This is an open-access article distributed under the terms of the Creative Commons Attribution License, which permits unrestricted use, distribution, and reproduction in any medium, provided the original author and source are credited. 
healthy adults, the tubular fluid of patients with kidney stones is often more supersaturated with calcium salts, which favors initiation and growth of crystals [18]. Like already described excessive calcium and oxalate secretion, low urine volume or a blend of both these factors may result in an increased calcium oxalate supersaturation. Also, extended accumulation of additional components, whether crystalline or organic are involved in clinical stones formation. Interaction of environmental factors and genetic susceptibility in varying fractions may lead to hypercalciuria and hyperoxaluria each. There are two types of hyperoxaluria: primary huyperoxaluria type 1 and 2 which is mainly caused by increased intestinal oxalate absorption as well as by rare autosomal recessive genetic disorders of oxalate synthesis, and the second one is enteric hyperoxaluria the leading cause of which is dietary habits such as low calcium intake coupled with high oxalate intake, malabsorptive disease, abnormalities of anion transporters found in both gut and kidney, and the modified gut flora which reduces the degradation of oxalate in the colon [19]. Various components in humans influence one's ability to promote or inhibit the process of stone formation and are named as promoters and inhibitors (Table 1).

\section{Medicinal and Dietary Plants in the Treatment and Prevention of Kidney Stones}

Herbal plants and their extracts are the best remedy for prevention and cure of urolithiasis as they play roles in controlling the process of crystallization events. Numerous studies all over the nation have reported several medicinal plants that have been applied as a therapeutic to urolithiasis and other ailments of urinary tract [20]. Although some of these medicinal plants have been validated scientifically and their efficacy has been determined by their phytochemical analysis, but this has not been done in most other cases. Even though the complete mechanism of action of plant based phytotherapeutic agents is lacking, they make up the majority of the medicines required given for urolithiasis. The renoprotective and antiurolithiatic effect of these medicinal plants has been reported globally (Table 2). The phytotherapy for kidney stone is highly divergent from allopathic treatment which acts basically on one aspect of urolithiatic pathophysiology as these plant based therapies demonstrate their effect on different stages of stone pathophysiology (Figures 1 and 2). Crystallization of the calcium oxalate stones is inhibited by a common compound of the medicinal plants named glycosaminoglycans (GAGs). Higher molecular weight phyto-molecules inhibit stone formation by inhibiting crystal nucleation, growth as well as aggregation in a manner similar to that of natural urinary inhibitors [21,22]. Grape fruit and lemon juice have been described to exert effects on stone crystallization under both in vivo and in vitro conditions $[23,24]$ apparently due to the formation of a more soluble compound than calcium oxalate i.e. calcium citrate. Crystal growth inhibition is also produced by the antilithogenic effect of Bergenia ligulata, Acalypha indica and Helicona hirsute. The medicinal use of Bergenia ligulata as an antiurolithic agent has been justified due to its potential to inhibit calcium oxalate crystal formation and because of its diuretic and hypermagneseuric activities [25].

A number of plants have displayed potential activities against different types of stones, such as those made up of magnesium ammonium phosphate and/or calcium oxalate. Ammania baccifera's

\begin{tabular}{|l|c|}
\hline Promoters & Calcium, Oxalate, Urate, Sodium, Low urine volume and Low urine pH \\
\hline Inhibitors & $\begin{array}{c}\text { Organic: Nephrocalcin, urinary prothrombin fragment-1 and osteopontin } \\
\text { Inorganic: Citrate and magnesium }\end{array}$ \\
\hline
\end{tabular}

Table 1: Promoters and inhibitors of calcium oxalate stone formation in humans [17].

\begin{tabular}{|c|c|c|}
\hline Plant & Mechanism of action & Reference \\
\hline Lygodium japonicum & $\begin{array}{c}\text { Reduces kidney peroxides, calcium, oxalate, uric acid and the number of } \\
\text { oxalate deposits in the urine. } \\
\text { Increases urinary citrate levels. }\end{array}$ & {$[8,38]$} \\
\hline Orthosiphon grandiflorus & Reduces crystal deposits Increases SOD and CAT activity & [39] \\
\hline Paronychia argentea & Reduces renal necrosis, renal cretinin and blood urea level. & [40] \\
\hline Pergularia daemia & Reduces serum urea, creatinine, nitrogen and uric acid levels. & [41] \\
\hline Quercus salicina & $\begin{array}{l}\text { Reduces MDA and serum creatinine level, oxidative stress and calcium level } \\
\text { in kidney }\end{array}$ & [42] \\
\hline Salvadora persica & Reduced urinary oxalate levels and deposition & [43] \\
\hline Selaginella lepidophylla & $\begin{array}{c}\text { Increases Urinary flow rate, glomerular filtration rate (GFR) } \\
\text { Decreased ROS, lipid-peroxidation and expression of renal cortical organic } \\
\text { anion transporter (OAT3). }\end{array}$ & [44] \\
\hline Agropyron repens & Reduces number and size of urinary stones and uric acid urinary secretion. & [45] \\
\hline Phylanthus nirvi & $\begin{array}{l}\text { Inhibits crystal aggregation and growth, interferes in the crystal morphology } \\
\text { by modifying the crystal-crystal and crystal matrix retention. Acts as an } \\
\text { antispasmodic and as a relaxant. }\end{array}$ & [46] \\
\hline Herniaria hersuta & $\begin{array}{l}\text { Eliminates pre existing kidney stones, decreases crystal size and increases } \\
\text { COD. Acts as a diuretic }\end{array}$ & [47] \\
\hline Tribulus terrestris & $\begin{array}{l}\text { Potent diuretic, khellin and visnagin prevent renal epithelial cell damage } \\
\text { caused by oxalate and COM. }\end{array}$ & [47] \\
\hline Cranbery juice & $\begin{array}{l}\text { Increase urinary citrate secretion, decreases urinary oxalate and calcium } \\
\text { excretion. }\end{array}$ & [47] \\
\hline Paronychia argentea & Lowering of urinary stone forming constituents, antioxidant activity. & [47] \\
\hline Grapefriut juice & Increases urinary citrate excretion. & [47] \\
\hline Lemonade juice & Increases urinary citrate excretion & [47] \\
\hline Pyracantha crenulata & Increases dieresis and lowering of urinary stone forming constituents. & [47] \\
\hline Boerhaavia diffusa & Acts as a diuretic and lowers excretion of oxalate and calcium. & [47] \\
\hline
\end{tabular}

Table 2: Various medicinal and dietary plants used in the treatment of kidney stones and the probable mechanism of action. 
Citation: Gupta S, Kanwar SS (2018) Phyto-molecules for Kidney Stones Treatment and Management. Biochem Anal Biochem 7: 362 . doi: 10.4172/2161-1009.1000362

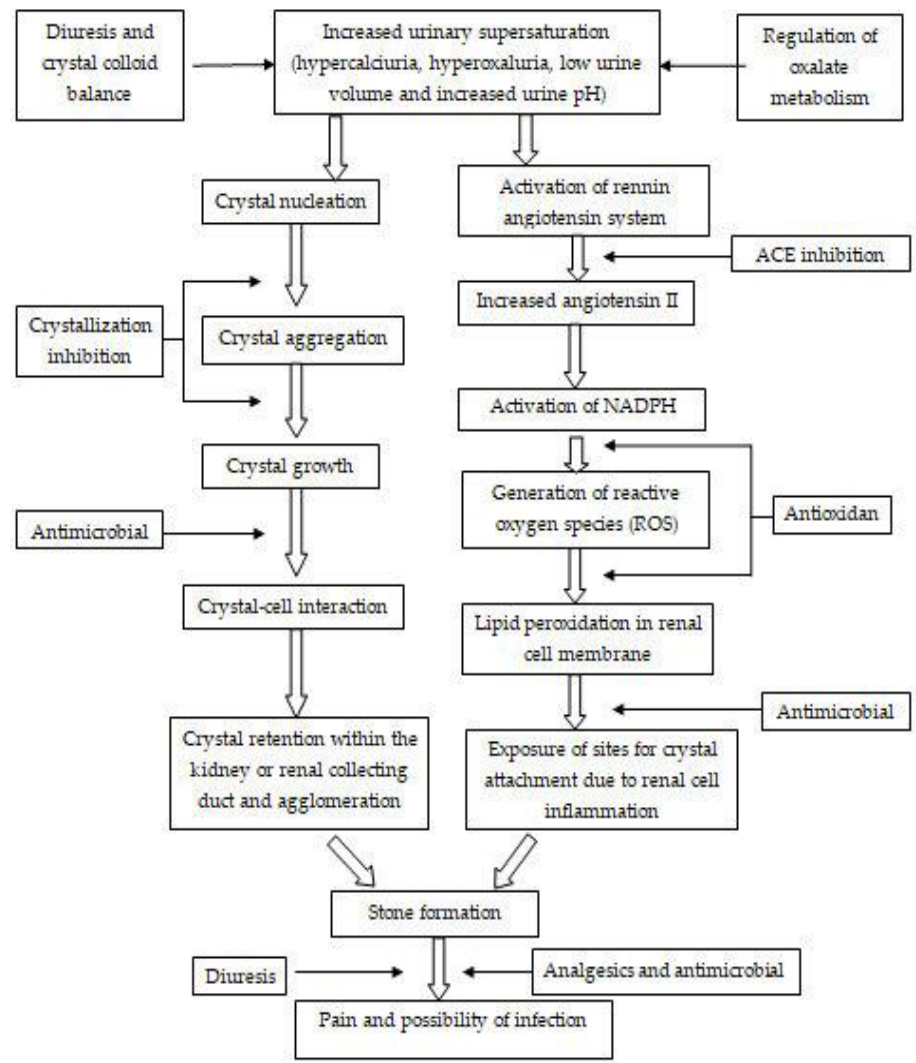

Figure 1: Probable mechanism of action of plants and phyto-molecules at different stages of stone pathophysiology.

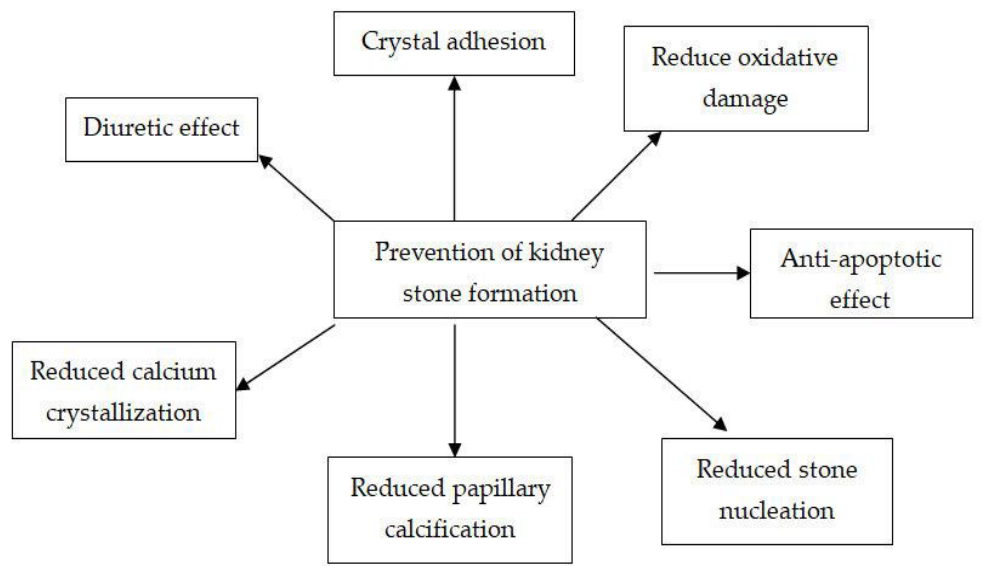

Figure 2: Strategies used by phyto-molecules for the prevention of formation of kidney stones.

ethanolic extracts exhibit preventive as well as therapeutic effects against phosphate stones, while the same activity has also been observed in the ethanolic extract of roots of Homonia riparia against calcium oxalate and struvite stones. Rotula aquatic's ethyl acetate extracts act as an antilithic agent against struvite and calcium oxalate stone. Phycocyanin, a well-known antioxidant exerts significant antiurolithiatic effect thereby markedly reduces oxalate levels in kidney stones. Even though the aqueous extract of Raphanus sativus are not related to a change in the affinity of muscarinic receptor of the bladder smooth musculature to cholinergic ligands, in the urinary bladder of rats they display antilithiatic activities against zinc or calcium oxalate crystals implants
[26]. In rats with nephrolithiasis a magnificent preventive effect has been displayed by Herniaria hirsute on $\mathrm{CaOx}$ stones; the effect did not seem to be mediated by biochemical or diuretic changes [27].

Green tea (Camellia sinensis) exhibit antioxidant and antiatherosclerotic properties, thereby, making it an effective dietary supplement for patients suffering from nephrolithiasis and urinary stones [28,29]. Green tea contains several molecules such as polyphenols, catechins, including epigallocatechin gallate (EGCG), epigallocatechin (GGC), epicatechin gallate (ECG), and epicatechin (EC) which are principally responsible for oxalate induced toxicity. 
In rat kidneys, green tree supplements, have presented prohibitory effects on the growth of crystal and also reduced oxalate excretion as well as inhibit the activities of $\gamma$-glutamyltranspeptidase and $\mathrm{N}$-acetyl$\beta$-D-glucosaminidase. While in rat model of kidney stones, brushite supersaturation is significantly decreased [28], Bcl-2 expression is enhanced, superoxide dismutase (SOD) activity is increased, and the apoptotic index is decreased [30]. Hence by and large formation of calcium oxalate stones in the kidneys is impeded by the antioxidant rich green tea [8].

In rat models of calcium oxalate stone formation ethanolic extracts of parsley or Petroselinum crispum has been observed to forbid the precipitation and nucleation of calcium oxalate, excretion of urinary proteins and urinary supersaturation and hence is used as a promising therapy for urolithiasis treatment [31]. Prevention of hyperoxaluria and dehydration of calcium oxalate by the ethanolic extract of this plant has been mainly attributed respectively to the greater concentration of chlorophyll and magnesium it contains [32]. By tuning the $\mathrm{pH}$ value of the urine to a point so that the calcium oxalate crystals remain as scattered particles and therefore can be removed, this plant encourages the exclusion of calcium oxalate crystals by maintaining these crystals as dispersed particles by regulating the $\mathrm{pH}$ at a particular value [8]. In ethylene glycol induced lithiatic rats, the ethanolic extracts of the seeds of a traditional therapeutic plant of Iran, Nigella sativa, depicted a decrease in the amount of calcium oxalate deposits and therefore has been employed in curing urinary stones [33]. This therapeutic effect of the ethanolic extract of these seeds was due to the major component of the seeds called thymoquinone. In the renal tubules of rats the decrease in the size and quantity of calcium oxalate deposits is because of the phytochemical components of the plant [34]. Horse gram (Dolichos biflorus), the seeds of which is used in making soups, is a nutritional and medicinal plant, native to India, [35] and has exhibited free radical-scavenging, anti-nephrotoxic as well as litholytic activities [3537]. It displays supreme anti-crystalization activities and hence will definitely be helpful in producing effective therapeutics for dissolution and prevention of kidney and urinary stones [38-48]. "Stinging Nettle" or Urtica dioica, a native of the nettle genus of Urticaceae family, which is utilized in Austrian medicine as tea has displayed a long history of favorable therapeutic effects against urinary ailments, notably for kidney and urinary tract stones. Crystal growth and calcium as well as oxalate deposits are prevented by its major bioactive phytochemicals such as flavonoids [49].

Several active phytochemicals such as alkaloids, coumains, saponins, flavonoids, sterols, terpenes and tannins are present in the crude aqueous-methanolic extract of Origanum vulgare's aerial parts that have reduced the amount of crystals produced in calcium oxalate metastable solutions, thereby, inhibiting various processes of nucleation and aggregation of the stones involved in the calcium oxalate stone formation [50]. In ethylene glycol induced urolithiatic rats, reduced deposition of stone producing components in the kidneys has been observed as an effect of the antiurolithiatric activity of aqueous plant extract of a traditional Thai medicine called Hibiscus sabdariffa and this acticity has been mainly attributed to some of its constituents like L-ascorbic acid, polyphenols, protocatechuic acid, hibiscus anthocyanins and quercetin [51]. Solanum xanthocarpum, or "yellow-fruit nightshade" and "Thai green eggplant" is a well-known traditional medicinal plant native to India, the seeds and fruits of which are widely used as foods and vegetables [52]. Due to its antioxidant and anti-lipid-peroxidation effects, the petroleum-ether extract of fruit of this plant displays nephro-protective activity which is mainly because of its rich composition of coumarins, triterpenes, steroidal glycol- alkaloids and saponins $[53,54]$. In calculi induced rats, the methanolic extract of this plant have shown beneficial effects in preventing and inhibiting supersaturation of calcium oxalate, crystalluria, renal hyperoxaluria and nephrolithiasis, as it exerts diuretic as well as antioxidant activities by increasing SOD and glutathione (GSH) levels [53]. In rats with ethylene glycol induced urolithiasis, the pathological changes caused by various lithogenic treatments such as damage to the renal function, oxidative stress, polyuria and crystalluria was shown to be prevented by the saponin rich fraction obtained from the fruits of $S$. xanthocarpum, and the effect was mainly accredited to its high antilithiatic activity. In vitro calcium oxalate crystal initiation and aggregation in artificial urine solution has been observed to be prohibited by this fraction, it also increases the concentration of glycosaminoglycan, a macromolecule found in the urine and also speeds up glomerular filtration [53]. Raspberry (Rubusidaeus, from Rosaceae family), predominantly used for therapeutic and nutritional use, is a commercial fruit crop of the European and Mediterranean countries, which has been reported to treat urinary tract stones even after acute administration [55]. Expressing a number of prophylactic activities [56], the epitheliial sodium channel and the aldosterone activity were observed to be inhibited by the methanolic extracts of raspberry due to its potent diuretic nature [57].

Because of the various bioactive phytochemicals including glycosides, saponins, tannins, quinones, triterpenoids and anthraquinones, Rubia cordifolia is used as a beneficial cure for cardiovascular ailments, diabetic foot ulcers and jaundice, and is also used as a natural colorant. The plant is also called as madder or Indian madder and is a native of the coffee family (Rubiaceae) $[58,59]$. Several kidney diseases have been proposed to be treated by the hydroalcoholic extract of this medicinal and nutritional plant as it reinstitutes magnesium levels, prevents proteinuria, expresses nephro-protective effects and curbs uric acid excretion, thereby inhibiting deposition and growth of calcium oxalate crystals [60]. The antioxidant properties of the above mentioned plant are predominantly responsible for its inhibitory effects [60]. Research has demonstrated that the methanolic extracts and juice of Punica granatum (pomegranate) contain a number of beneficial phytochemicals that promote the relaxation of the urinary and biliary tract muscles and thus help in releasing the stones from the kidneys exhibiting anti-hypercalciuric and antiurolithiatic activity, thereby attracting appreciable attention for its use in the prevention of renal calcium oxalate stones. Because of its antioxidant and anti-lipidperoxidation activity, it plays a significant role in preventing oxidative renal tubular damage [61]. Besides, it plays a role in decreasing reactive oxygen species (ROS), nuclear factor $-\kappa \mathrm{B}(\mathrm{NF}-\kappa \mathrm{B})$, inducible nitric oxide synthase (iNOS), ) and p38-mitogen-activated protein kinase (p38-MAPK) levels as well as managing the concentration of creatinine, urea and ureic acid [62-64].

Strong anti-urolithiatic activity in nucleation assays conducted in vivo have been displayed by the leaf and stem extracts of various Terminalia sp. (such as T. bellirica, T. chebula, Z. mays, T. catappa, and T. terrestris) with T. catappa and T. chebula extracts showing moderate activities and T. bellirica extracts exhibiting good activities. There are many reports where different plant extracts have demonstrated antiurolithiatic activities as evaluated by in vitro nucleation assays, and thus these are promising plants with anti-urolithiatic activities [65]. Recently, a synergistic herbal formulation comprising of therapeutically effective amounts of herbal constituents/ingredients such as those drawn from five different plant parts of Achyranthes aspera (Aghada); Hordeum vulgare's (Yav/Satu) seeds, Crataeva nurvala's (Varuna) bark; and stem, kand i.e. yam and root of Musa sapientum (Banana); along 
with other pharmaceutically acceptable additives have been found to be successful in curing urinary tract disorders such as inflammation and urinary stent related problems as well as kidney stones [66].

\section{Phyto-molecules in the Inhibition of Kidney Stone Formation}

The effectiveness of several dietary interventions, as a favorable method for protection from kidney diseases has been recommended by several studies either as a part of, or separate from the inherited or genetic factors. In order to minimize the probability of kidney stone recurrence and prevent the formation and growth of crystals, thus treating urolithiasis, several nutritional plants and their phytochemicals can be used as dietary supplements or added into the main diet. Although there is a lack of knowledge about the molecular basis underlying the prophylactic effect of these phyto-therapeutics, a number of therapeutic herbs and their components are employed for treatment of kidney disorders (Table 3 ). The antioxidative property of various antiurolithitic nutraceuticals is found to be accountable for inhibiting the leading component of urolithiasis i.e. nucleation, aggregation and growth of calcium oxalate crystals. With more than 8,000 structural variants, phyto-phenols have been found in several vegetables and fruits that constitute the most abundant dietary antioxidants [67], which display notable repressive activities against the oxidative stress-related kidney dysfunctions. The antioxidative effect of main antioxidants, epicatechin and catechin found in plants sources like grape seeds and green tea [68] is accredited predominantly to either metal chelating and radical scavenging properties or to the revamping effects on enzymes and transcription factors [69], which provides shielding effect against formation of renal stones, oxidative stress associated with renal failure, and renal injuries [70,71]. In COM-treated NRK-52E renal proximal tubular cell line, catechins reestablished the proteolysis of caspase 3 and mitochondrial membrane potential because of its increased SOD activity [72]. This elevated SOD activity of catechins successfully produced inhibitory effects on the renal papillary calcification and enhancement of COM papillary calculi [70-73]. 8-Hydroxy-20-deoxyguanosine (8-OHdG), OPN and MDA activity was also regulated by catechins in the ethylene glycolinduced rat model of nephrolithiasis [72]. An essential catechin, epigallocatechin-3-gallate (EGCG) acutely diminished the ability of Madin-Darby canine kidney (MDCK) cells to bind to calcium oxalate monohydrate crystals which after administration, reduced the $a$-enolase protein expression (responsible for binding) on the renal tubular cell surface which was mainly responsible for such an attenuation reaction $[8,74]$. Dosmin, a flavonoid glycoside, exhibits protective effects in the kidney against oxidative stress, nephro-toxicity and diabetic nephropathy. Mostly found in vegetasbles and citrus fruits, dosmin is a polyphenol with inherent antiurolithiatic activity
[75]. It possesses inhibitory effects on lipid peroxidation, modulates the Bax and p53 proteins expression and enhances the antioxidant enzymes activity which is responsible for its renoprotective properties [76]. Since catechins restore the diameter of the capillaries and vessels in the cortex, inactivate the degeneration of glomeruli and tubules, and reduce the capillary hyper-permeability, they blocks the process of calcium oxalate stone formation in rat model of nephrolithiasis [77]. Diosmin maintain acidic conditions in the urine which increases the urine volume, decreases urinary proteins and enhances potassium and magnesium levels [78]. Like dosmin, antioxidant and anti-lithiatic activity has been observed in several other flavone glycosides, such as rutin, quercetin, and hyperoside. Rutin either alone or in combination with curcumin efficiently inhibited stone formation and a number of plants such as apple peels and black tea are the dietary sources of this nutraceutical [79].

These phytophenols modulated the filtration rates in the glomerulas and prevented the growth and aggregation of COM crystals [80]. The deterrent mechanism of these phytochemicals has been possible because of their anti-inflammatory effect in addition to the antioxidant activities. Such encouraging diuretic, anti-inflamatory, antioxidant and hypo-uricemic effects have also been demonstrated by quercetin and hyperoside which are predominantly found in vegetables and fruits) [81]. In rats with induced hyperoxaluria, quercetin displays a promising antioxidative effect, owing to its ability to promote serum PON1. By enhancing the SOD and catalase activities, these therapeutic bioflavonoids display antioxidant activity against renal tubular cell injury, they also exhibit anti-apoptotic effects as well as restraining activities on accumulation of oxalate crystals, and hence have been reported to control renal lithiasis [8].

\section{Mechanism of Action of Plants and their Constituents in the Prevention and Treatment of Kidney Stones}

Plants and their phytomolecules act on several different elements of urolithiasis pathophysiology and have been found to be influential in curing, prophylaxis and prevention of recurrence of kidney stone. Acting as a diuretic, preventing the calcium oxalate crystal formation, enhancing glycosaminoglycan levels, decreasing urinary oxalate and calcium excretion as well as raising the urinary citrate secretion are some of the means through which these plants and their phytochemicals prevent and treat kidney stones Figure 2. In order to provide protection against kidney stones the dietary phyto-molecules demonstrate several other mechanisms, such as preventive effect on crystallization and aggregation of crystals due to increased magnesium secretion, antioxidative, nephroprotective, cytoprotective and antispasmodic effects.

One of the major problems with kidney stones is its reoccurrence.

\begin{tabular}{|c|c|c|}
\hline Phyto-molecule & Mechanism of action & Reference \\
\hline Catechin & $\begin{array}{l}\text { Increases SOD activity. Decreases mitochondrial membrane potential (MMP), Caspase-3 activity, renal } \\
\text { calcium crystallization,.renal papillary calcification, calcium oxalate monohydrate and papillary calculus } \\
\text { formation. }\end{array}$ & {$[8,72,73]$} \\
\hline Epigallocatechin-3-gallate (EGCG) & $\begin{array}{l}\text { Reduces free-radical production, crystal binding capability, urinary oxalate excretion, activities of urinary } \\
\text { gammaglutamyl transpeptidase and } \mathrm{N} \text {-acetylglucosaminidase and } \alpha \text {-enolase expression. }\end{array}$ & {$[8,74]$} \\
\hline Diosmin & $\begin{array}{l}\text { Reduces capillary hyper-permeability and glomeruli and tubules degeneration, Diameter of the capillaries } \\
\text { and vessels in the cortex is restored. }\end{array}$ & {$[8,77]$} \\
\hline Rutin & Prevents stone formation. Inhibits calcium oxalate urolithiasis. & {$[8,80]$} \\
\hline Quercetin & $\begin{array}{l}\text { Possesses hypo-uricemic, and anti-inflammatory activities. } \\
\text { Exhibits inhibitory effect on the deposition of calcium oxalate crystal } \\
\text { Decreases cell viability, lipid peroxidation, formation of urinary crystal deposit and oxidative damage. } \\
\text { Increases Serum paraoxonase } 1 \text { (PON1) }\end{array}$ & {$[8,81]$} \\
\hline
\end{tabular}

Table 3: Phyto-molecules used for treatment of kidney stones and their mode of action. 
Several drugs, such as diuretics like alkali-citrate and thiazide are used to prevent recurrence of hypercalciuria and hyperoxaluria, even though they possess a very low activity [64]. Therefore, several studies have been conducted that reveal the potent therapeutic activities of medicinal plants for renal calculi. These plants and their phytomolecules inhibit crystallization by reducing supersaturation, regulate oxalate metabolism, modify the crystalloid-colloid imbalance, and demonstrate lithotropic activity which prevent renal calculi recurrence. For example, B. ligulata rhizome extract represses the calcium oxalate crystal's precipitation due to quelling effects on aggregation, growth and formation of crystals [25]. Reoccurrence of stone formation which is in its early stages can be effectively inhibited by leaf extract of Launaea procumbens [82]. Quercus salicina extract are involved in reducing oxidative stress, thereby inhibiting the buildup of kidney calcium concentration. In human diet many diverse plants and their isolated natural polyphenols have been found to be beneficial as a natural cure for kidney stones which has been attributed to their several preventive mechanisms that include: down-regulation of serum PON1, inhibition of growth and deposition of calcium oxalate crystals, enhancing the activity of antioxidant enzymes, reduction of proteinuria, hyperoxaluria and hypocitraturia and suppression of the attachment and internalization of calcium oxalate monohydrate crystals to epithelial tubular cells [8].

\section{Conclusion}

Over a number of decades, urolithiasis or kidney stones have become one of the most important constraints in human health globally and imparts a big therapeutic threat because of the lack of effective treatments, greater reccurence rates and its multi-factorial etiology. Various events such as urinary supersaturation, nucleation, growth, aggregation and retention of crystals in the renal tubular epithelial cells are involved in the mechanism of formation of stones. In recent years, it has been observed that herbal therapy has emerged as an alternative and better approach for the treatment of kidney stones and urolithiasis, as most of the conventional therapies available till date are not $100 \%$ effective. Yet the human investigations that have been done to determine the efficacy of medicinal and nutritional plants and their phytoconstituents in prevention and treatment of kidney stones are quite restricted. The potency of A. repens (L.), D. biflorus L., H. sabdariffa L., P.granatum L., and Phyllanthus niruri L. has been confirmed by clinical trials. Several phytomolecules (mainly dietary polyphenols) have been proposed as promising dietary supplements for prevention of urolithiasis which include hyperoside, catechin, curcumin, epicatechin, rutin, quercetin, diosmin and EGCG. Therefore to sum up, the data obtained from the available literature presupposes that prevention and intervention of urolithiasis can be achieved by medicinal as well as dietary plants and their phytonutrients. In the case of safety and effectiveness, these molecules can be refined and processed to produce natural drugs. Critical clinical trials are required in further research and investigations to validate the efficacy and safety of these constituents in patients with kidney stones.

\section{Acknowledgments}

This research received no specific grant from any funding agency in the public, commercial, or not-for-profit sectors.

\section{References}

1. Pareta SK, Patra KC, Harwansh R (2011) In-vitro calcium oxalate crystallization inhibition by Achyranthes indica linn. Hydroalcoholic extract: An approach to antilithiasis. Int J Pharm Bio Sci 2: 432-437.

2. Butterweck V, Khan SR (2009) Herbal Medicines in the Management of Urolithiasis: Alternative or Complementary? Planta Med 75: 1095-1103.
3. Gindi S, Methra T, Chandu BR, Boyina R, Dasari V (2013) Antiurolithiatic and invitro anti-oxidant activity of leaves of Ageratum conyzoides in rat. World $J$ Pharm Pharm Sci 2: 636-649.

4. Heron S, Yarnell E (1998) Recurrent kidney stones: A naturopathic approach Altern Complement Ther 4: 60-67.

5. Sellaturay S, Fry C (2008) The metabolic basis for urolithiasis. Surgery 26 136-139.

6. Panigrahi PN, Dey S, Jena SC (2016) Urolithiasis: Critical Analysis of Mechanism of Renal Stone Formation and Use of Medicinal Plants as Antiurolithiatic Agents. AJAVA 11: 9-16.

7. Arya P, Pandey S, Verma V (2017) Kidney stone formation and use of medicinal plants as antiurolithiatic agents. UJPR 2: 42-48.

8. Nirumand MC, Hajialyani M, Rahimi R, Farzaei MH, Zingue S, et al. (2018) Dietary Plants for the Prevention and Management of Kidney Stones: Preclinical and Clinical Evidence and Molecular Mechanisms. Int J Mol Sci 19: 765.

9. Houston DM, Moore AEP (2009) Canine and feline urolithiasis: Examination of over 50,000 urolith submissions to the Canadian veterinary urolith centre from 1998 to 2008 . Can Vet J 50: 1263-1268.

10. Bartges JW, Kirk C, Lane LF (2004) Update: Management of calcium oxalate uroliths in dogs and cats. Vet Clin North Am: Small Anim Pract 34: 969-987.

11. Parrah JD, Hussain SS, Moulvi BA, Singh M, Athar H (2010) Bovine uroliths analysis: A review of 30 cases. Isr J Vet Med 65: 103-107.

12. Khan SR (2004) Crystal-induced inflammation of the kidneys: Results from human studies, animal models and tissue-culture studies. Clin Exp Nephrol 8: $75-88$.

13. Harsoliya MS, Pathan JK, Khan N, Bhatt D, Patel VM (2011) Effect of ethanolic extracts of Bergenia ligulata, Nigella sativa and combination on calcium oxalate urolithiasis in rats. Int J Drug Formulat Res 2: 268-280.

14. Osborne CA, Lulich JP, Kruger JM, Ulrich LK, Koehler LA (2009) Analysis of 451,891 canine uroliths, feline uroliths and feline urethral plugs from 1981 to 2007: Perspectives from the Minnesota Urolith center Vet Clin North Am Small Anim Pract 39: 183-197.

15. Worcester EM, Coe FL (2008) Nephrolithiasis. Prim Care 35: 369-391.

16. Miller NL, Evan AP, Lingeman JE (2007) Pathogenesis of renal calculi. Urol Clin North Am 34: 295-313.

17. Coe FL, Evan AP, Worcester E (2005) Kidney stone disease. J Clin Invest 115 2598-2608.

18. Ratkalkar VN, Kleinman JG (2011) Mechanisms of Stone Formation. Clin Rev Bone Miner Metab 9: 187-197.

19. Aggarwal PK, Narula S, Kakkar M, Tondon C (2013) Nephrolithiasis: Molecular Mechanism of Renal Stone Formation and the Critical Role Played by Modulators. BioMed Res Int.

20. Tiwari A, Soni V, Londhe VP, Bhandarkar A, Bandawane D (2012) An overview on potent indigenous herbs for urinary tract infirmity: Urolithiasis. Asian J Pharmaceut Clin Res 5: 7-12.

21. Pareta SK, Patra KC, Mazumder PM, Sasmal D (2011) Establishing the Principle of Herbal Therapy for Antiurolithiatic Activity: A Review. J Pharma Toxicol 6: 321-332.

22. Atmani F, Slimani Y, Mimouni M, Hacht B (2003) Prophylaxis of calcium oxalate stones by Herniaria hirsuta on experimentally induced nephrolithiasis in rats. BJU Int 92: 137-140.

23. Trinchieri A, Lizzano R, Bernardi P, Nicola M, Pozzino F, et al. (2002) Effect of acute load of grapefruit juice on urinary excretion of citrate and urinary risk factors for renal stone formation. Dig Liver Dis 34: 160-165.

24. Seltzer MA, Low RK, McDonald M, Shami GS, Stoller ML (1996) Dietary manipulation with lemonade to treat hypocitruric calcium nephrolithiasis. J Urol 156: 907-909.

25. Bashir S, Gilani AH (2009) Antiurolithic effect of Bergenia ligulata rhizome: An explanation of the underlying mechanisms. J Ethnopharmacol 122: 106-116.

26. Prasad KVSRG, Sujatha D, Bharti K (2007) Herbal drugs in urolithiasis: A review. Pharmacog Rev 1: 175-179. 
Citation: Gupta S, Kanwar SS (2018) Phyto-molecules for Kidney Stones Treatment and Management. Biochem Anal Biochem 7: 362 . doi: 10.4172/2161-1009.1000362

27. Atmani F, Khan SR (2000) Effects of an extract from Herniaria hirsuta on calcium oxalate crystallization in vitro. BJU Int 85: 621-625

28. Rodgers A, Mokoena M, Durbach I, Lazarus J, de Jager S, et al. (2016) Do teas rich in antioxidants reduce the physicochemical and peroxidative risk factors for calcium oxalate nephrolithiasis in humans? Pilot studies with Rooibos herbal tea and Japanese green tea. Urolithiasis 44: 299-310.

29. Kim JW, Choi JS, Yoon GS, Yang EK, Kim DY (2005) Effect of green tea on calcium oxalate stone formation and excretion in ethylene glycol-treated rats. Korean J Urol 46: 299-305.

30. Itoh Y, Yasui T, Okada A, Tozawa K, Hayashi Y (2005) Preventive effects of green tea on renal stone formation and the role of oxidative stress in nephrolithiasis. J Urol 173: 271-275.

31. Al-Yousofy F, Gumaih H, Ibrahim H, Alasbahy A (2017) Parsley! Mechanism as antiurolithiasis remedy. Am J Clin Exp Urol 5: 55-62.

32. Kuzma P, Druzynska B, Obiedzinski M (2014) Optimization of extraction conditions of some polyphenolic compounds from parsley leaves (Petroselinum crispum). Acta Sci Pol Technol Aliment 13: 145-154.

33. Hayatdavoudi P, Rad AK, Rajaei Z, Hadjzadeh MA (2016) Renal injury, nephrolithiasis and Nigella sativa: A mini review. Avicenna J Phytomed 6: 1-8.

34. Hajzadeh MA, Mohammadian N, Rahmani Z, Rassouli FB (2008) Effect of thymoquinone on ethylene glycol-induced kidney calculi in rats. Urol J 5: 149155.

35. Mathew LE, Sindhu G, Helen A (2014) Dolichos biflorus exhibits antiinflammatory and antioxidant properties in an acute inflammatory model. J Food Drug Anal 22: 455-462.

36. Atodariya U, Barad R, Upadhyay S, Upadhyay U (2013) Anti-urolithiatic activity of Dolichos biflorus seeds. J Pharmacogn Phytochem 2.

37. Singh RG, Behura SK, Kumar R (2010) Litholytic property of Kulattha (Dolichous biflorus) vs potassium citrate in renal calculus disease comparative study. J Assoc Physicians India 58: 286-289.

38. Cho HJ, Bae WJ, Kim SJ, Hong SH, Lee JY, et al. (2014) The inhibitory effect of an ethanol extract of the spores of Lygodium japonicum on ethylene glycolinduced kidney calculi in rats. Urolithiasis 42: 309-315.

39. Akanae W, Tsujihata M, Yoshioka I, Nonomura N, Okuyama A (2010) Orthosiphon grandiflorum has a protective effect in a calcium oxalate stone forming rat model. Urol Res 38: 89-96.

40. Bouanani S, Henchiri C, Migianu-Griffoni E, Aouf N, Lecouvey M (2010) Pharmacological and toxicological effects of Paronychia argentea in experimental calcium oxalate nephrolithiasis in rats. J Ethnopharmacol 129 $38-45$

41. Vyas B, Vyas R, Joshi S, Santani D (2011) Antiurolithiatic activity of whole-plan hydroalcoholic extract of Pergularia daemia in rats. J Young Pharm 3: 36-40.

42. Moriyama MT, Suga K, Miyazawa K, Tanaka T, Higashioka M, et al. (2009) Inhibitions of urinary oxidative stress and renal calcium level by an extract of Quercus salicina Blume/Quercus stenophylla Makino in a rat calcium oxalate urolithiasis model. Int J Urol 16: 397-401.

43. Geetha K, Manavalan R, Venkappayya D (2010) Control of urinary risk factors of stone formation by Salvadora persica in experimental hyperoxaluria. Methods Find Exp Clin Pharmacol 32: 623-629.

44. Mirian ECM, Juanita NM, Christophe BO, Estela MC (2013) Molecula mechanisms involved in the protective effect of the chloroform extract of Selaginella lepidophylla (Hook. et Grev.) Spring in a lithiasic rat model. Urolithiasis 41: 205-215.

45. Brardi S, Imperiali P, Cevenini G, Verdacchi T, Ponchietti R (2012) Effects of the association of potassium citrate and Agropyrum repens in renal stone treatment: Results of a prospective randomized comparison with potassium citrate. Arch Ital Urol Androl 84: 61-67.

46. Micali S, Sighinolfi M, Celia A, de Stefani S, Grande M, et al. (2006) Can Phyllanthus niruri affect the efficacy of extracorporeal shock wave lithotripsy for renal stones? A randomized, prospective, long-term study. J Urol 176: 10201022.

47. Pareta SK, Patra KC, Mazumder PM, Sasmal D (2010) Boerhaavia diffusa Linn aqueous extract as curative agent in ethylene glycol induced urolithiasis. Pharmacologyonline 3: 112-120.
48. Saha S, Verma RJ (2014) Evaluation of hydro-alcoholic extract of Dolichos biflorus seeds on inhibition of calcium oxalate crystallization. J Herb Med 5: 41-47.

49. Zhang H, Li N, Li K, Li P (2014) Protective effect of Urtica dioica methanol extract against experimentally induced urinary calculi in rats. Mol Med Rep 10 157-3162.

50. Khan A, Bashir S, Khan SR, Gilani AH (2011) Antiurolithic activity of Origanum vulgare is mediated through multiple pathways. BMC Complement Altern Med 11: 96 .

51. Laikangbam R, Devi MD (2012) Inhibition of calcium oxalate crystal deposition on kidneys of urolithiatic rats by Hibiscus sabdariffa L. extract. Urol Res 40 211-218.

52. Kumar S, Pandey AK (2014) Medicinal attributes of Solanum xanthocarpum fruit consumed by several tribal communities as food in vitro antioxidant anticancer and anti HIV perspective. BMC Complement Altern Med 14: 112.

53. Patel PK, Patel MA, Saralai M, Gandhi T (2012) Antiurolithiatic effects of Solanum xanthocarpum fruit extract on ethylene-glycol-induced nephrolithiasis in rats. J Young Pharm 4: 164-170.

54. Hussain T, Gupta RK, Sweety K, Eswaran B, Vijayakumar M, et al. (2012) Nephroprotective activity of Solanum xanthocarpum fruit extract against gentamicin-induced nephrotoxicity and renal dysfunction in experimental rodents. Asian Pac J Trop Med 5: 686-691.

55. Anttonen MJ, Karjalainen RO (2005) Environmental and genetic variation of phenolic compounds in red raspberry. J Food Compos Anal 18: 759-769.

56. Ghalayini IF, Al-Ghazo MA, Harfeil MN (2011) Prophylaxis and therapeutic effects of raspberry (Rubus idaeus) on renal stone formation in Balb/c mice. Int Braz J Urol 37: 259-267.

57. Zhang Y, Zhang Z, Yang Y, Zu X, Guan D, et al. (2011) Diuretic activity of Rubus idaeus $L$ (Rosaceae) in rats. Trop J Pharm Res 10.

58. Bhatt P, Kushwah A (2013) Rubia cordifolia overview: A new approach to treat cardiac disorders. Int J Drug Dev Res 5: 47-54.

59. Deshkar N, Tilloo S, Pande VA (2008) Comprehensive review of Rubia cordifolia Linn. Pharmacogn Rev 2: 124-134.

60. Divakar K, Pawar A, Chandrasekhar S, Dighe S, Divakar G (2010) Protective effect of the hydro-alcoholic extract of Rubia cordifolia roots against ethylene glycol induced urolithiasis in rats. Food Chem Toxicol 48: 1013-1018.

61. Bagri P, Ali M, Aeri V, Bhowmik M, Sultana S (2009) Antidiabetic effect of Punica granatum flowers: Effect on hyperlipidemia, pancreatic cells lipid peroxidation and antioxidant enzymes in experimental diabetes. Food Chem Toxicol 47: 50-54.

62. Tugcu V, Kemahli E, Ozbek E, Arinci YV, Uhri M, et al. (2008) Protective effect of a potent antioxidant, pomegranate juice, in the kidney of rats with nephrolithiasis induced by ethylene glycol. J Endourol 22: 2723-2732.

63. Ilbey YO, Ozbek E, Simsek A, Cekmen M, Somay A, et al. (2009) Effects of pomegranate juice on hyperoxaluria-induced oxidative stress in the rat kidneys. Ren Fail 31: 522-531.

64. Rathod N, Biswas D, Chitme H, Ratna S, Muchandi I, et al. (2012) Antiurolithiatic effects of Punica granatum in male rats. J Ethnopharmacol 140 234-238.

65. Ram J, Moteriya P, Chanda S (2016) Effect of decoction extract of some medicinal plants on calcium oxalate crystallization. Asian J Pharm Clin Res 9: 70-76.

66. Patankar SB (2011) Herbal composition for the treatment of kidney stone and other urinary tract disorders. US9259441B2.

67. Han X, Shen T, Lou H (2007) Dietary polyphenols and their biological significance. Int J Mol Sci 8: 950-988.

68. Mendoza-Wilson AM, Glossman-Mitnik D (2006) Theoretical study of the molecular properties and chemical reactivity of (+)-catechin and (--)-epicatechin related to their antioxidant ability. J Mol Struct THEOCHEM 761: 97-106.

69. Higdon JV, Frei B (2003) Tea catechins and polyphenols: Health effects, metabolism, and antioxidant functions. Crit Rev Food Sci Nutr 43: 89-143.

70. Amengual-Cladera E, Nadal-Casellas A, Gómez-Pérez Y, Gomila I, Prieto RM et al. (2011) Phytotherapy in a rat model of hyperoxaluriahe antioxidant effects 
Citation: Gupta S, Kanwar SS (2018) Phyto-molecules for Kidney Stones Treatment and Management. Biochem Anal Biochem 7: 362 . doi: 10.4172/2161-1009.1000362

Page 8 of 8

of quercetin involve serum paraoxonase1 activation. Exp Biol Med 236: 11331138.

71. Khan SA, Priyamvada S, Farooq N, Khan S, Khan MW (2009) Protective effect of green tea extract on gentamicin-induced nephrotoxicity and oxidative damage in rat kidney. Pharmacol Res 59: 254-262.

72. Zhai W, Zheng J, Yao X, Peng B, Liu M, et al. (2013) Catechin prevents the calcium oxalate monohydrate induced renal calcium crystallization in NRK$52 \mathrm{E}$ cells and the ethylene glycol induced renal stone formation in rat. BMC Complement Altern Med 13: 228.

73. Grases F, Prieto RM, Fernandez-Cabot RA, Costa-Bauzá A, Tur F (2015) Effects of polyphenols from grape seeds on renal lithiasis. Oxid Med Cell Longev 813737.

74. Kanlaya R, Singhto N, Thongboonkerd V (2016) EGCG decreases binding of calcium oxalate monohydrate crystals onto renal tubular cells via decreased surface expression of alpha-enolase. J Biol Inorg Chem 21: 339-346.

75. Crespo M, Galvez J, Cruz T, Ocete M, Zarzuelo A (1999) Anti-inflammatory activity of diosmin and hesperidin in rat colitis induced by TNBS. Planta Med 65: 651-653.

76. Rehman MU, Tahir M, Quaiyoom Khan A, Khan R, Lateef A, et al. (2013)
Diosmin protects against trichloroethylene-induced renal injury in Wistar ratslausible role of $\mathrm{p53}$, Bax and caspases. Br J Nutr 110: 699-710.

77. Noorafshan A, Karbalay-Doust S, Karimi F (2013) Diosmin reduces calcium oxalate deposition and tissue degeneration in nephrolithiasis in rats: A stereological study. Korean J Urol 54: 252-257.

78. Prabhu VV, Sathyamurthy D, Ramasamy A, Das S, Anuradha M, et al. (2016) Evaluation of protective effects of diosmin (a citrus flavonoid) in chemicalinduced urolithiasis in experimental rats. Pharm Biol 54: 1513-1521.

79. Pastukhov AV, Levchenko LA, Sadkov AP (2006) Spectroscopic study on binding of rutin to human serum albumin. J Mol Struct 842: 60-66.

80. Ghodasara J, Pawar A, Deshmukh C, Kuchekar B (2010) Inhibitory effect of rutin and curcumin on experimentally-induced calcium oxalate urolithiasis in rats. Pharmacognosy Res 2: 388-392.

81. Zhu W, Xu YF, Feng Y, Peng B, Che JP, et al. (2014) Prophylactic effects of quercetin and hyperoside in a calcium oxalate stone forming rat model. Urolithiasis 42: 519-526.

82. Makasana A, Ranpariya V, Desai D, Mendpara J, Parekh V (2014) Evaluation for the anti-urolithiatic activity of Launaea procumbens against ethylene glycolinduced renal calculi in rats. Toxicol Rep 1: 46-52. 